\title{
Age and Growth of the Leopard Grouper, Mycteroperca rosacea, in the Southern Gulf of California, México ${ }^{1}$
}

\author{
7. Gabriel Díaz-Uribe, ${ }^{2}$ Fuan F. Elorduy-Garay, ${ }^{3}$ and Ma. Teresa González-Valdovinos ${ }^{4}$
}

\begin{abstract}
Growth of the leopard grouper, Mycteroperca rosacea (Streets, 1877), was analyzed in its natural habitat. Age determination was based on the reading of otoliths, and the method was validated under three main criteria: (1) proportionality, (2) seasonality, and (3) concordance with another method. Otolith growth is proportional to organism growth, with a slight degree of allometry, and the otolith registers the growth of the individual, even at advanced ages. The opaque growth zone in the otolith is deposited once a year, between July and October. Thus, taken together, one opaque and one hyaline mark represent an annual cycle. Back-calculated lengths-at-age agreed reasonably well with observed lengths-at-age at the time of capture, considering that back-calculated lengths represent an exact age (birthday), and observed lengths are taken at an intermediate age between birthdays. Fish length and otolith age data were fitted to the von Bertalanffy growth function by two methods: (1) linear regression (Ford-Walford and Beverton), using transformed data, and (2) nonlinear regression, by iteration. Although the nonlinear regression gave a fit with unbiased error, parameters resulting from linear regressions had a better biological meaning for the species. The resulting parameters were compared with those reported for other species of the family Serranidae.
\end{abstract}

The LeOPARD GROUPER, Mycteroperca rosacea (Streets, 1877), is found in subtropical shallow coastal waters, in a restricted geographical area from Magdalena Bay (Baja California

1 This study was partially funded by Dirección General de Investigación Científica y Superación AcadémicaSecretaría de Educación Pública (DIGICSA-SEP) and Dirección de Estudios de Posgrado e Investigación (DEPI)-966509 research projects. J.F.E.-G. received fellowships from Comisión para el Fomento de Actividades Académicas (COFAA) and Estímulo al Desempeño Docente (EDD) at the Instituto Politécnico Nacional. Manuscript accepted 9 August 2000.

2 Instituto de Recursos, Universidad del Mar, A.P. 47, Puerto Ángel, Oaxaca, 70902, México.

${ }^{3}$ Departamento de Pesquerías y Biología Marina, Centro Interdisciplinario de Ciencias Marinas (CICIMAR), A.P. 592, La Paz, B.C.S., 23000, México (telephone: 52 (1) 12253 44; fax: 52 (1) 12253 22; E-mail: jelorduy@redipn.ipn.mx).

${ }^{4}$ Departamento de Biología Marina, Universidad Autónoma de Baja California Sur, A.P. 19-B, La Paz, B.C.S., 23080, México.

Pacific Science (2001), vol. 55, no. 2:171-182 (C) 2001 by University of Hawai'i Press.

All rights reserved
Sur) to Banderas Bay (Jalisco), including the Gulf of California (Thomson et al. 1987, Heemstra 1995). The family Serranidae forms an important part of the catches from the artisanal fishery of Baja California Sur, and the leopard grouper surpasses other species both in volume and frequency of catches (Rodríguez-Medrano 1990). The biology of the leopard grouper is poorly known. There are works referring to its description and taxonomic status (Rosenblatt and Zahuranec 1987), distribution and abundance in $\mathrm{La} \mathrm{Paz}$ Bay, B.C.S. (Villavicencio 1983), and feeding habits (Bermúdez-Almada and García-Laguna 1985), but previous studies on age and growth for this species are lacking.

Individual growth rate, age structure, and age of first maturity and recruitment are useful parameters for the evaluation of populations, and the confidence level at which they are estimated depends, in large part, on the method used for age determination (Ricker 1979, Sparre and Venema 1992). The reading of scales and otoliths has been the most frequently used method for age determination of fish. In slow-growing, long-lived 
species, the growth marks are unreadable near the edge of scales, causing an underestimation of age. Otoliths have proven more useful for age determination in this kind of organism (Boehlert 1985, Devries and Frie 1996). Considering the long life cycle and slow growth rate of species composing the family Serranidae (Manooch 1987), we considered that otoliths would be the most reliable structure for age and growth analysis of the leopard grouper. Even the reading of otoliths does not ensure a priori that this method of age determination is dependable. It must be demonstrated that the marks used to determine age are related to a specific time interval, and that they can be observed for most of the life cycle of the species (Beamish and McFarlane 1983, Casselman 1983). Only in this way can the bias in estimation of growth parameters be reduced, or at least known, and the consequences in resource management appreciated (Beamish and McFarlane 1983).

The von Bertalanffy growth function has proven to be a good model in studies of growth because of the applicability of its parameters in more complex models describing population dynamics (Sparre and Venema 1992). Because of the commercial importance of the leopard grouper, the estimation of growth parameters is especially valuable because of its relevance to fishery management. In this study we analyze the validity of otolith reading for age determination of Mycteroperca rosacea caught in the Bay of $\mathrm{La} \mathrm{Paz}$, B.C.S., and vicinities, and the fitting of data to the Von Bertalanffy growth function is also presented.

\section{MATERIALS AND METHODS}

From January 1991 to June 1992 individuals of $M$. rosacea were selected monthly from both commercial and experimental catches made around Espíritu Santo and Cerralvo Islands, located off the western coast of the Gulf of California (Figure 1). A maximum of 15 fish per length interval $(50 \mathrm{~mm})$, per month, was randomly selected from the catches. Each fish was measured in total (TL) and standard (SL) lengths and gutted weight
(GW). Whenever possible, total weight (TW) and sex were also determined. After measuring, both sagittae otoliths were extracted by an oblique cut at the cranial basis. At the laboratory, otoliths were washed with soap and tap water and stored dry.

Before age determination, a small subsample of otoliths was subjected to different combinations of high temperatures (300$400^{\circ} \mathrm{C}$ ) and times (5-30 $\left.\mathrm{min}\right)$ to improve the contrast between marks (Elorduy-Garay and Díaz-Uribe 1994). The temperature-time combination with best contrast was chosen and applied to all otoliths considered in the study.

Otolith readings and measurements were made using a dissecting microscope, an ocular micrometer, and reflected illumination, at $10 \times$ total magnification. Reading consisted of the counting of growth marks and the determination of edge type (i.e., opaque or hyaline). Each otolith was read twice independently. When both readings were identical the otolith was declared readable, and the number of marks (rings) and edge type were assigned to the corresponding fish. Whenever there were differences, otoliths were submitted to a third reading. If the third reading agreed with either of the previous two readings it was assigned as definitive; if not, the otolith was considered unreadable and discarded.

Three types of morphometric relationships were analyzed: TL versus SL, GW versus TW, and TL versus GW. The first two were evaluated using linear regression by least squares and Student's $t$-test under the null hypothesis $a=0, b=0$, and $R^{2}=0$ $(\alpha=0.05)$. The third relationship was evaluated by the potential model $Y=a x^{b}$ using nonlinear regression by least squares, with the program FISHPARM 3.1 (Prager et al. 1989); in this case, Student's $t$-test was ran under the null hypothesis $b=3$ and $R^{2}=0(\alpha=0.05)$.

The use of otoliths for age determination of $M$. rosacea was validated with three basic criteria (Beamish and McFarlane 1983, Casselman 1983):

(1) Proportionality between otolith growth and fish growth was tested by selecting a stratified subsample, as a function of fish 


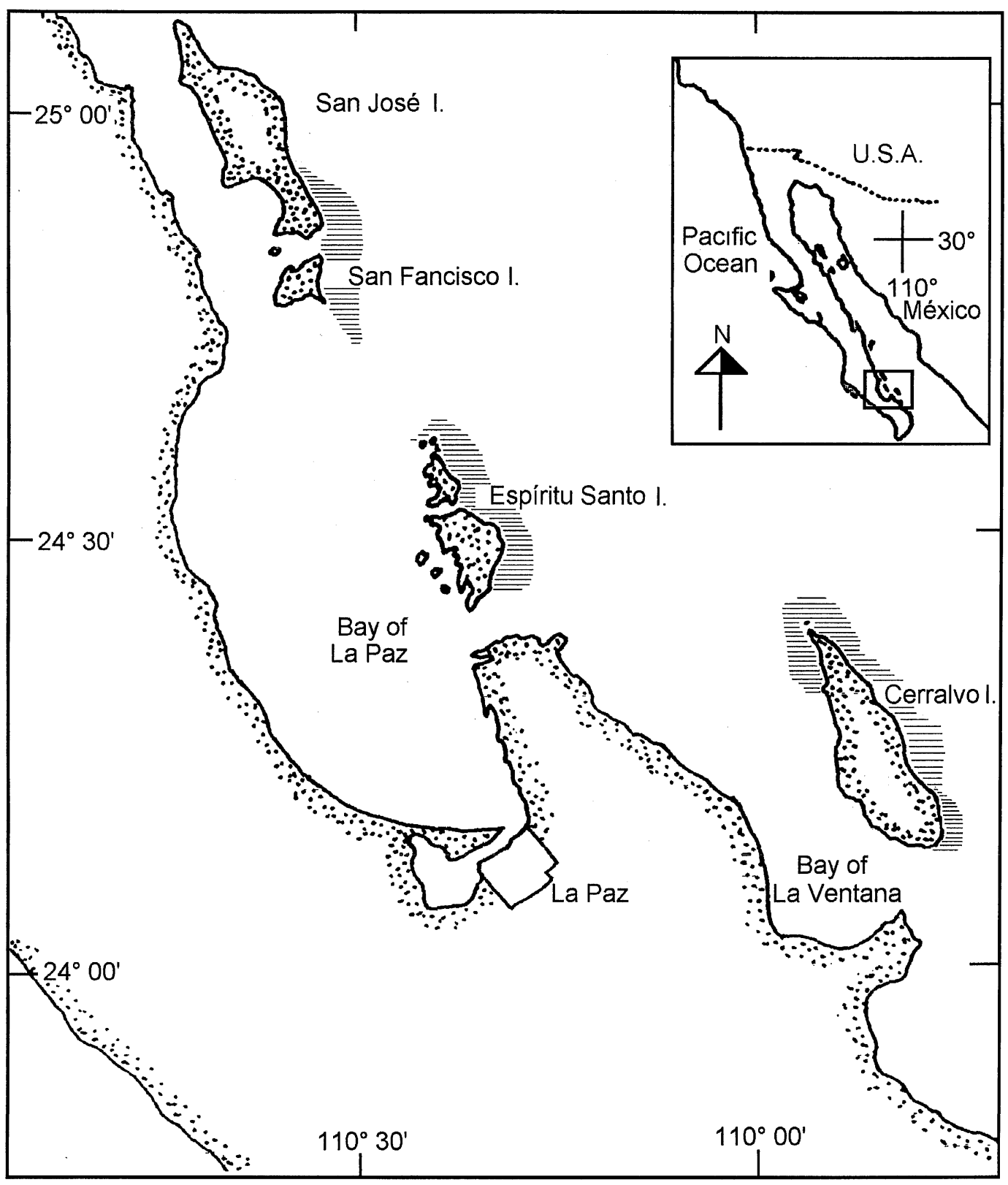

FIgURE 1. Fishing areas from which the samples of $M$. rosacea were obtained.

length and independent of the month of capture. A maximum of 20 pairs of otoliths per length interval was selected. The otoliths were measured in long diameter (OLD) and long radius (OLR). Data on otolith growth and fish growth were adjusted to a potential model.

(2) Seasonality in the formation of growth marks was analyzed by the monthly frequency of otolith edge type, using the total sample. 
This information was compared with the sea surface temperature in southern $\mathrm{La} \mathrm{Paz} \mathrm{Bay.}$ The Secretaría de Desarrollo Social, Delegación B.C.S., kindly provided temperature data.

(3) Concordance with another method was analyzed by the back-calculation of lengths at past ages, as a reference method. The subsample used was the same as that used in the proportionality analysis. At this stage, the radii at each growth mark (annuli) were measured in each otolith. Average lengthat-age was estimated using the equation:

$$
L_{i}=a^{*} R_{i}^{b}
$$

where $L_{i}$ is the length of the fish when the otolith radius was $R_{i} ; a$ and $b$ are the parameters of the regression of fish length on otolith radius from the proportionality analysis. Back-calculated lengths were compared with observed lengths at the time of capture.

Individual growth was calculated fitting the age-length data to the Von Bertalanffy growth function:

$$
L_{t}=L_{\infty}\left[1-e^{-k\left(t-t_{0}\right)}\right]
$$

where $L_{t}$ is the average length of the fish at age $t ; L_{\infty}$ is the average maximum length of the analyzed stock; $k$ is the growth coefficient; and $t_{0}$ is the parameter of origin of the growth curve.

Two separate methods were used to derive the growth function. In the first method (designated LRC) we followed the FordWalford procedure to calculate $L_{\infty}$ and the Beverton procedure to calculate $k$ and $t_{0}$ (Ricker 1975, Sparre and Venema 1992). The second method utilized a nonlinear regression analysis (NLR) with the program FISHPARM 3.1 (Prager et al. 1989). Confidence intervals $(\alpha=0.05)$ were calculated for each parameter and compared with those calculated by the LRC method.

\section{RESULTS}

In total 769 fish were sampled during the study period, except for the months of June, November, and December 1991 when catches were low, and it was impossible for us to survey at sea. Individuals in the sample ranged from 283 to $975 \mathrm{~mm}$ TL, but $90 \%$ of the fish were between 350 and $700 \mathrm{~mm}$ TL (Figure 2). Sex was determined for $16 \%$ of the sample, comprising fish $286-808 \mathrm{~mm}$ in length (TL). None of the fish had virginal gonads.

Because of the small dispersion of data, the linear model fitted to the TL-SL relationship explains nearly $98 \%$ of the variability $(P<0.01)$ (Table 1). The GW-TW relationship presented the same behavior, with 99\% $(P<0.01)$ of explained variance (Table $1)$. Ordinates at the origin were not significantly different from zero $(P>0.05)$ in both regressions. Therefore, the standard length of the leopard grouper represents an average of $86-88 \%$ of the total length, and the gutted weight represents an average of $87-90 \%$ of the total weight.

The potential model fitted to the TL-GW relationship explains $97 \%$ of the observed variability $(P<0.01)$, so it has an important predictive value. The coefficient $b=2.97$ is not significantly different from $3(P>0.05)$, so the leopard grouper exhibits isometric growth (Table 1).

Heating the otoliths at $325^{\circ} \mathrm{C}$ for $25 \mathrm{~min}$ was the combination that rendered best results. Under these conditions, opaque rings turned yellow, and hyaline ones turned dark brown. The immersion of these otoliths in glycerin several minutes before the readings notably improved the contrast between rings. Nearly $95 \%$ of the otoliths were used in age determinations. The remaining were considered unreadable, because of lack of agreement in the number of rings (2\%) or lack of agreement both in the number of rings and edge type (3\%).

Otolith growth is strongly correlated to overall fish growth. All the correlation coefficients $(r)$ were significant $(P<0.01)$, in spite of the fact that data present higher dispersion than the previous regressions (Table 2). In every correlation where TL is involved the exponent is significantly greater than 1 $(P<0.01)$, whereas in every correlation where $\mathrm{GW}$ is involved the exponent is significantly different from $3(P<0.01)$. This means that there is a certain degree of allom- 


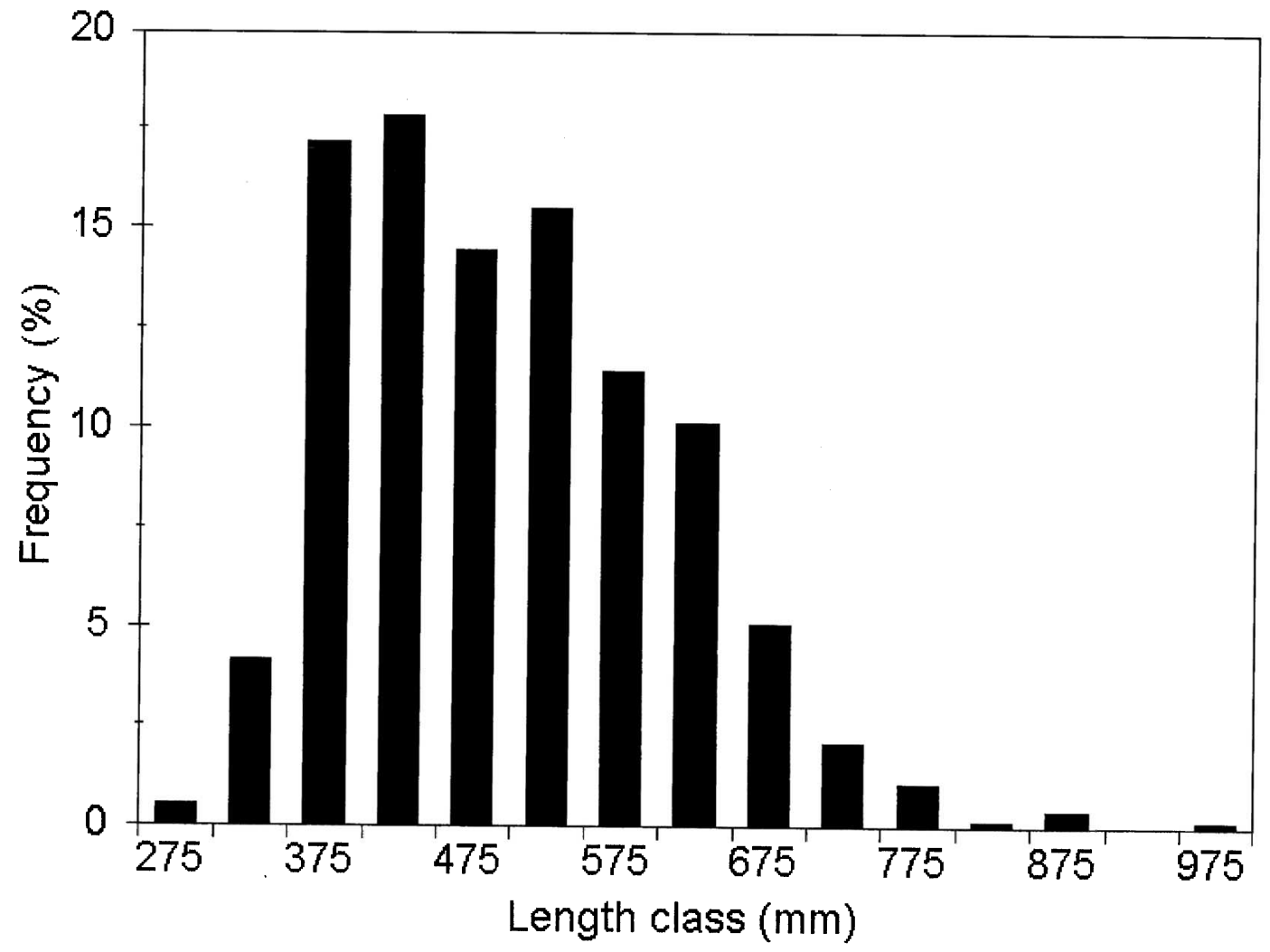

FIGURE 2. Frequency distribution of size classes (TL) for the whole sample of $M$. rosacea.

etry, in which the fish grows proportionally faster than the otolith.

In 1991 the frequency of individuals with opaque otolith edges was low in January and February and highest between July and October (Figure 3). Although there is no information for June, November, and December in that year, the tendency in the other months indicates that individuals with opaque otolith edges predominated $(>50 \%)$ from June to November. The frequency of individuals with opaque otolith edges was again low at the beginning of 1992. This pattern follows the temperatures registered in the Bay of La Paz.

TABLE 1

Morphometric Relationships Involving Body Length and Weight in M. rosacea

\begin{tabular}{lcccccr}
\hline \hline & \multicolumn{5}{c}{ Parameters } \\
\cline { 3 - 7 } Relationship & $n$ & $a$ & SE $(a)$ & $b$ & SE $(b)$ & $R^{2}$ \\
\hline TL - SL & 762 & -10.583 & 12.998 & 0.872 & $4.36 \times 10^{-3}$ & 0.981 \\
GW - TW & 111 & 5.997 & 120.312 & 1.128 & $8.51 \times 10^{-3}$ & 0.994 \\
TL - GW & 762 & $1.43 \times 10^{-5}$ & $1.58 \times 10^{-6}$ & 2.970 & $1.70 \times 10^{-2}$ & 0.973 \\
\hline
\end{tabular}

Note: Total length (TL) - standard length (SL) (function, $y=a+b x$ ); gutted weight $(\mathrm{GW})$ - total weight (TW) (function, $y=a+b x$ ); total length (TL) - gutted weight $(\mathrm{GW})$ (function, $\left.y=a x^{b}\right) . R^{2}$, coefficient of determination; $n$, sample size. 
TABLE 2

Morphometric Relationships between Otolith Features and Body Length and Weight in M. rosacea

\begin{tabular}{lccccc}
\hline \hline & \multicolumn{5}{c}{ Parameters } \\
\cline { 2 - 6 } Relationship & $a$ & SE $(a)$ & $b$ & SE $(b)$ & $R^{2}$ \\
\hline OLD vs. TL & 10.640 & 1.416 & 1.656 & 0.055 & 0.8360 \\
OLR vs. TL & 34.640 & 3.276 & 1.639 & 0.055 & 0.8357 \\
OLD vs. GW & 0.088 & 0.035 & 4.241 & 0.159 & 0.7928 \\
OLR vs. GW & 1.538 & 0.452 & 4.288 & 0.161 & 0.7977 \\
\hline
\end{tabular}

Note: All relationships were fitted to the potential model $y=a x^{b}$. Linear dimensions are expressed in mm and weight in g. OLD, otolith long diameter; OLR, otolith long radius; TL, fish total length; GW, fish gutted weight, $n=187$ for all cases.

In general, the temperature increase correlates well with the increase of opaque otolith edge development and vice versa. There is no evidence of another season with a high degree of opaque otolith edge development in the population. Thus, a set of one opaque and one hyaline ring represents a year in the life of these fish.

The back-calculation of lengths at past ages showed that the readings on otoliths were consistent, except for the age groups of 12 or more years. In these, the back-

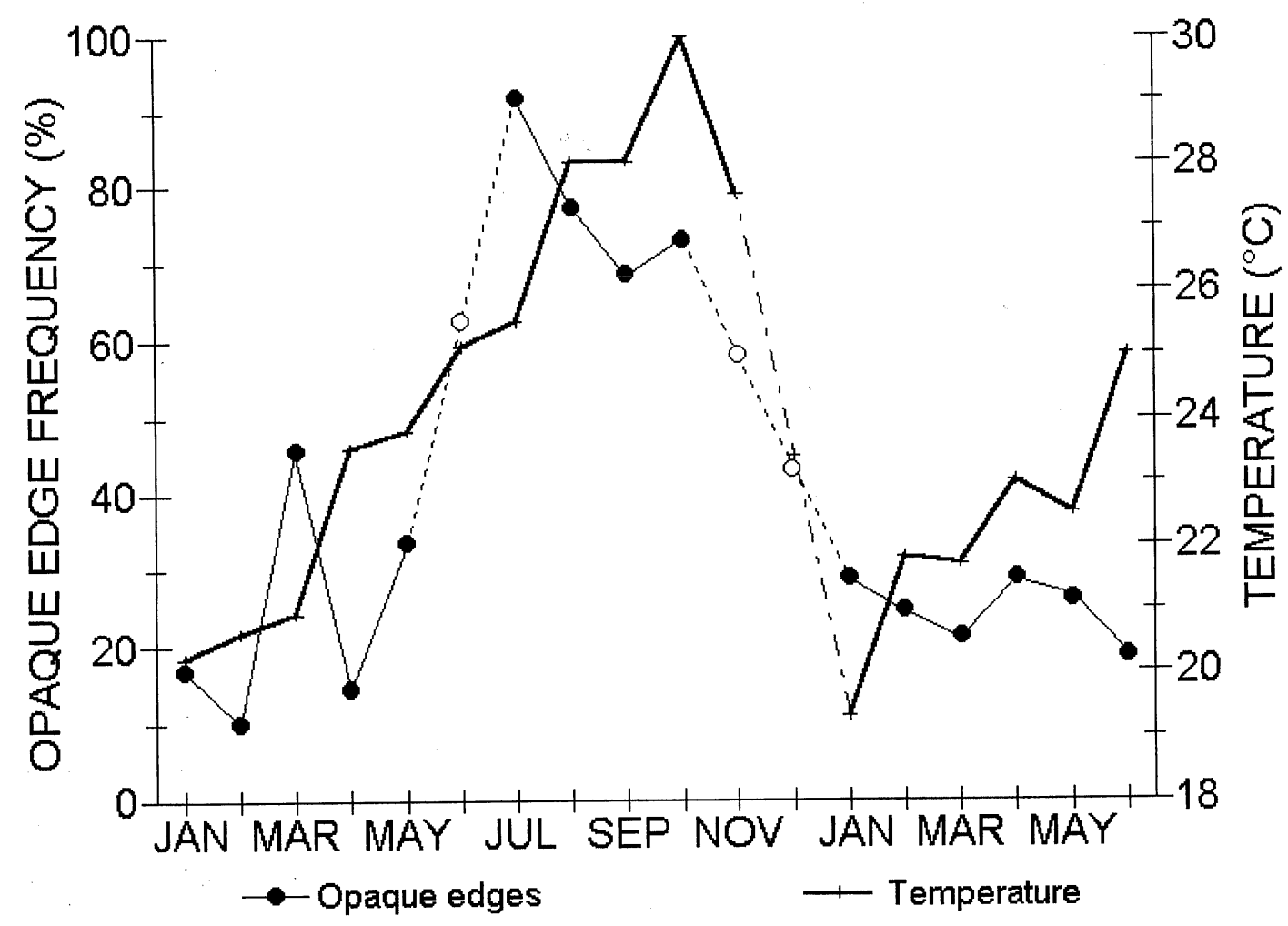

FIGURE 3. Monthly frequency of individuals of $M$. rosacea exhibiting opaque otolith edges in the total sample of 769 fish, plotted with mean monthly sea surface temperature in the Bay of $\mathrm{La} \mathrm{Paz}$. 


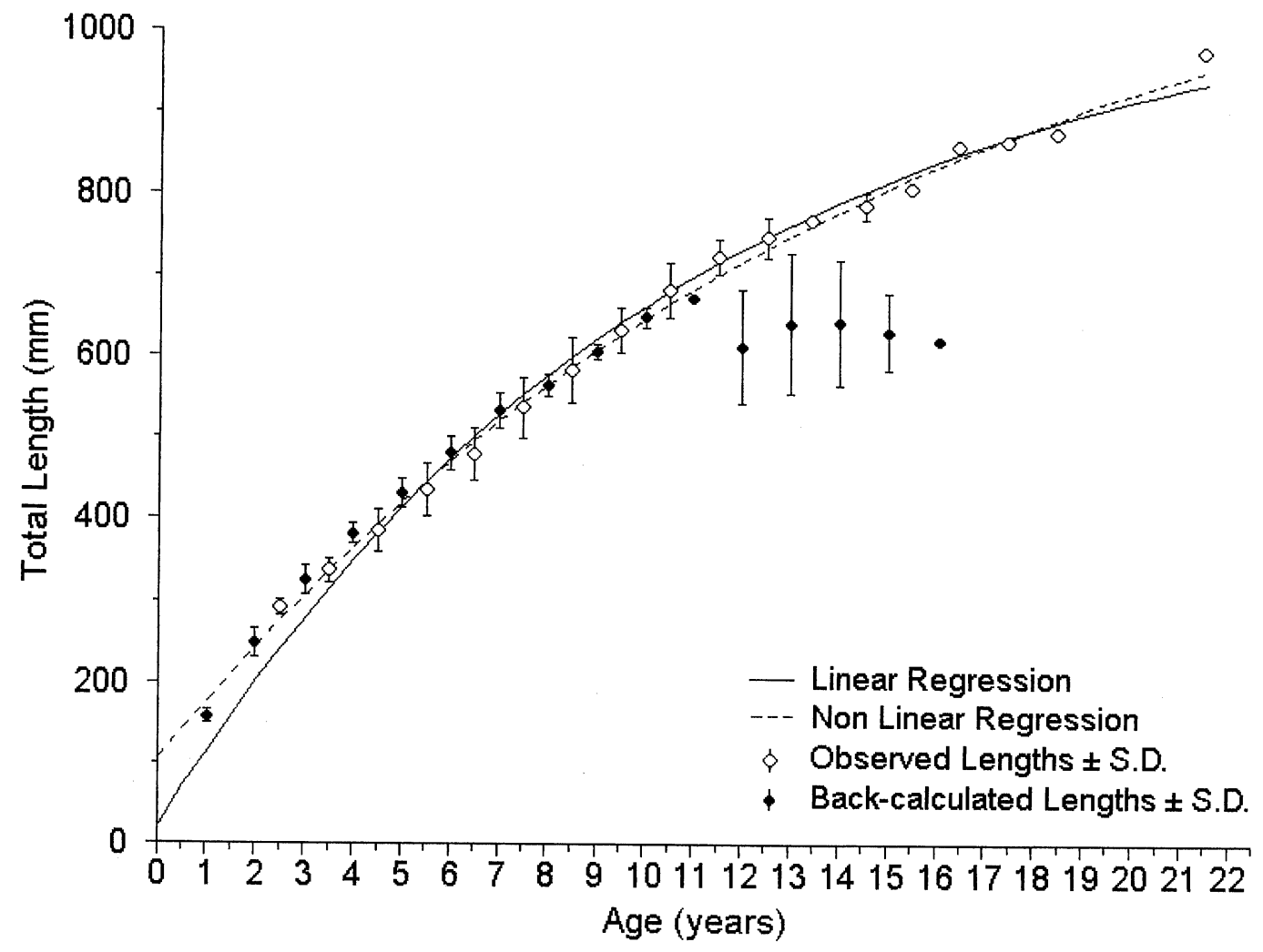

FIGURE 4. Growth curves (in total length, TL) of the leopard grouper fitted by two methods: NLR (nonlinear regression), using FISHPARM 3.1 (Prager et al. 1989) and LRC (linear regression). Back-calculated lengths-at-age (closed circles), and observed lengths-at-age (open circles) are shown.

calculated lengths were, on average, shorter than for the other age groups (Figure 4). Because of the small number of fish older than $11 \mathrm{yr}$, it is not possible to evaluate if the bias in the averages was due to a random factor or to an intrinsic factor of the otolith (Table 3).

The growth model was fitted to a set of data containing the back-calculated lengthsat-age, up to $11 \mathrm{yr}$, and the observed lengthsat-age (Table 4). Estimated parameters in the LRC method were different from those in the NLR method (Table 5). According to the standard error estimated by the NLR method, $L_{\infty}$ could vary from 1142 to $1310 \mathrm{~mm}(\mathrm{df}=28 ; P=0.05)$; the $L_{\infty}=1083$ estimated by the LRC method is outside that range. The growth coefficient $k$ also showed differences between the two estimation methods. The $95 \%$ confidence interval for $k$ estimated by the NLR method is 0.0567 to $0.0750 \mathrm{yr}^{-1}$; the value of $k\left(0.0925 \mathrm{yr}^{-1}\right)$ estimated by the LRC method is outside this range. Although the nonlinear regression analysis (NLR) explains a larger amount of the variance in the data set, the goodness of fit should be evaluated in view of the biological information of the species (Figure 4).

\section{DISCUSSION}

Although sex could be determined only for a small number of fish, we can state that juveniles were not present in the sample. Even the smaller fish in our samples were adults, which agrees with the reports of Heemstra (1995), who referred to juveniles of $M$. rosacea as 
TABLE 3

Back-Calculated Lengths at Specified Ages for M. rosacea

\begin{tabular}{|c|c|c|c|c|c|c|c|c|c|c|c|c|c|c|c|c|c|}
\hline \multirow[b]{2}{*}{$n$} & \multirow{2}{*}{$\begin{array}{l}\text { Age } \\
\text { Group }\end{array}$} & \multicolumn{16}{|c|}{ Annuli } \\
\hline & & I & II & III & IV & $\mathrm{V}$ & VI & VII & VIII & IX & $X$ & XI & XII & XIII & XIV & $X V$ & XVI \\
\hline 2 & 2 & 172 & 270 & & & & & & & & & & & & & & \\
\hline 18 & 3 & 164 & 271 & 342 & & & & & & & & & & & & & \\
\hline 32 & 4 & 162 & 265 & 342 & 392 & & & & & & & & & & & & \\
\hline 23 & 5 & 152 & 244 & 329 & 390 & 442 & & & & & & & & & & & \\
\hline 18 & 6 & 158 & 251 & 325 & 380 & 427 & 483 & & & & & & & & & & \\
\hline 23 & 7 & 150 & 232 & 312 & 383 & 450 & 505 & 555 & & & & & & & & & \\
\hline 15 & 8 & 150 & 227 & 304 & 366 & 418 & 470 & 530 & 579 & & & & & & & & \\
\hline 9 & 9 & 147 & 223 & 288 & 353 & 396 & 445 & 494 & 555 & 609 & & & & & & & \\
\hline 10 & 10 & 164 & 234 & 306 & 362 & 416 & 465 & 526 & 552 & 609 & 656 & & & & & & \\
\hline 7 & 11 & 172 & 263 & 338 & 384 & 428 & 469 & 512 & 553 & 592 & 634 & 671 & & & & & \\
\hline$\underline{2}$ & 12 & 155 & 191 & 229 & 270 & 309 & 354 & 403 & 442 & 484 & 527 & 572 & 623 & & & & \\
\hline 1 & 13 & 172 & 249 & 336 & 383 & 432 & 462 & 505 & 550 & 594 & 628 & 664 & 700 & 737 & & & \\
\hline 1 & 14 & 172 & 249 & 291 & 336 & 383 & 423 & 462 & 505 & 550 & 594 & 628 & 664 & 700 & 737 & & \\
\hline$\underline{1}$ & 15 & 138 & 172 & 210 & 249 & 291 & 336 & 373 & 412 & 453 & 494 & 538 & 571 & 606 & 641 & 676 & \\
\hline 1 & 16 & 138 & 172 & 210 & 240 & 274 & 309 & 336 & 364 & 393 & 423 & 453 & 484 & 517 & 550 & 583 & 618 \\
\hline $\mathrm{Wt}$ & Avg. & 157 & 248 & 324 & 381 & 430 & 479 & 531 & 563 & 604 & 647 & 671 & 611 & 640 & 642 & 630 & 618 \\
\hline SD & & 6.82 & 16.41 & 16.52 & 12.16 & 16.01 & 19.01 & 20.77 & 12.59 & 7.74 & 10.88 & & 69.07 & 85.84 & 76.61 & 46.59 & \\
\hline
\end{tabular}

Note: Weighted averages and standard deviations are shown. $n$ is the number of fish in each age group. Underlined data were not used for averaging.

\section{TABLE 4}

Observed Mean Lengths of Individuals of $M$. rosacea at Various Ages as Determined by Otolith Annual Marks

\begin{tabular}{ccrr}
\hline \hline Age $(\mathrm{yr})$ & TL $(\mathrm{mm})$ & \multicolumn{1}{c}{ SD } & $n$ \\
\hline $2+$ & 291 & 7.616 & 4 \\
$3+$ & 336 & 13.730 & 29 \\
$4+$ & 385 & 25.232 & 142 \\
$5+$ & 434 & 31.899 & 141 \\
$6+$ & 477 & 30.924 & 98 \\
$7+$ & 535 & 37.180 & 119 \\
$8+$ & 582 & 39.179 & 84 \\
$9+$ & 631 & 26.179 & 67 \\
$10+$ & 681 & 32.472 & 24 \\
$11+$ & 722 & 20.124 & 8 \\
$12+$ & 747 & 23.629 & 3 \\
$13+$ & 768 & 3.536 & 2 \\
$14+$ & 786 & 15.556 & 2 \\
$15+$ & 808 & - & 1 \\
$16+$ & 860 & - & 1 \\
$17+$ & 866 & - & 1 \\
$18+$ & 875 & - & 1 \\
$21+$ & 975 & - & 1 \\
\hline
\end{tabular}

Note: TL, total length; SD, standard deviation of mean length; $n$, sample size. smaller than $300 \mathrm{~mm}$ TL. The same author reported a maximum length of $700 \mathrm{~mm}$ for the species, but Thomson et al. (1987) and Allen and Robertson (1994) mentioned that this species can reach up to $1000 \mathrm{~mm}$ and $12.2 \mathrm{~kg}$ of weight, although they did not specify the kind of length and weight. This

\section{TABLE 5}

Growth Parameters for $M$. rosacea Calculated by Two Regression Methods

\begin{tabular}{lccccc}
\hline \hline & \multicolumn{2}{c}{$\begin{array}{c}\text { Nonlinear } \\
\text { Regression }\end{array}$} & & \multicolumn{2}{c}{$\begin{array}{c}\text { Linear } \\
\text { Regression }\end{array}$} \\
\cline { 2 - 3 } Parameter & Average & SE & & Average & SE \\
\hline$L_{\infty}$ & 1226 & 41.16 & & 1083 & - \\
$k$ & 0.06586 & 0.00447 & & 0.09245 & - \\
$t_{0}$ & -1.393 & 0.1798 & & -0.2446 & - \\
$r^{2}$ & 0.99603 & - & & 0.98034 & - \\
\hline
\end{tabular}

Note: $L_{\infty}$ in $\mathrm{mm}, k$ in year ${ }^{-1}$, and $t_{0}$ in years. 
divergence is shown in the length distribution found in our study sample. Although most individuals caught are less than $700 \mathrm{~mm}$ TL, larger fish are encountered; our study registered lengths to $915 \mathrm{~mm} \mathrm{TL}$, close to the maximum reported by Thomson et al. (1987) and Allen and Robertson (1994).

Heating otoliths is a useful technique to improve contrast and ease the reading of $M$. rosacea otoliths; each mark acquires a differential coloration.

The allometry phenomenon in the relationship of otolith size to fish size has been reported for several species, and discussed from the physiological point of view (Simkiss 1973). The extreme case in which otoliths grow to a maximum size and then grow only in thickness has been documented for several species of soles (Williams and Bedford 1973). In $M$. rosacea the evidence indicates that the fish grows at a higher rate than the otolith. The value of $b=1.656$ indicates that when the fish increases its length $100 \%$, the otolith grows approximately 53\%. Other species, such as Ocyurus chrysurus (Manooch and Drennon 1987) and Lutjanus peru (RochaOlivares and Gómez-Muñoz 1993), have $b$ values near 1.6. However, otolith growth does not completely stop in these cases. Although there are no precise criteria specifying the critical level at which allometry would adversely affect age determination by examination of otoliths, the values obtained for $M$. rosacea do not seem to cause problems, because even at the oldest ages, rings could be counted and measured.

Whenever growth marks are deposited periodically, it is possible to assess this process using the ratio of edge types (opaque or hyaline) in otoliths (Williams and Bedford 1973). The prevalence of opaque edges in summer-autumn and hyaline edges in winter-spring represents a defined pattern in $M$. rosacea otoliths.

We consider that reading of otoliths is a consistent method for determining age at the time of capture, because observed lengths were generally larger than back-calculated lengths at each age. Comparison was made taking into account that each method gives complementary information. That is, average lengths by age at the time of capture represent the length at an intermediate age between two birthdays, because at the time of age assignment most otoliths show a fraction of edge, indicating that the birthday has already passed. However, back-calculated lengths at previous ages represent the exact birthday lengths. Therefore, the consistency of the two methods was analyzed by the following criteria: (1) each back-calculated length belongs to an exact age $(1,2,3, \ldots$, etc.); (2) each length at the time of capture belongs to an intermediate age $(1.5,2.5, \ldots$, etc.). In this way, both data sets intercalate reasonably well between 3 and 11 yr of age, within what could be the individual growth curve. Because juveniles younger than $3 \mathrm{yr}$ and adults older than $11 \mathrm{yr}$ were scarcely represented in our sample, we consider only ages within this range to be accurately reflected by otolith characteristics.

Individual growth is a process that implies a change in body mass in a determined time period. To express this phenomenon in terms of length, von Bertalanffy developed his model under the hypothesis that organisms grow isometrically. That is, that the organism keeps the same body form during the growth period. Whenever this happens, the change in body mass or respiratory surface due to growth is proportional to the change in length cubed or squared, respectively. Pauly (1979) found that many fish species do not comply with this criterion, so the Von Bertalanffy growth model (VBGM) represents only a special case. The value of $b=2.97$ in the leopard grouper is not significantly different from 3, therefore the use of the VBGM can be considered adequate in this case.

Fitting the growth curve by NLR is a statistically powerful method because no transformation of the data is required and the error of the parameters is estimated in an unbiased way (Prager et al. 1989). But this is a condition a priori, and the estimations must be evaluated as a function of the biological implications of the adjusted parameters. Several authors have discussed the close relationship of $W_{\infty}$ and $k$ with the biological cycle of species (Pauly 1979, Manooch 1987, Sparre and Venema 1992). Munro and Pauly 


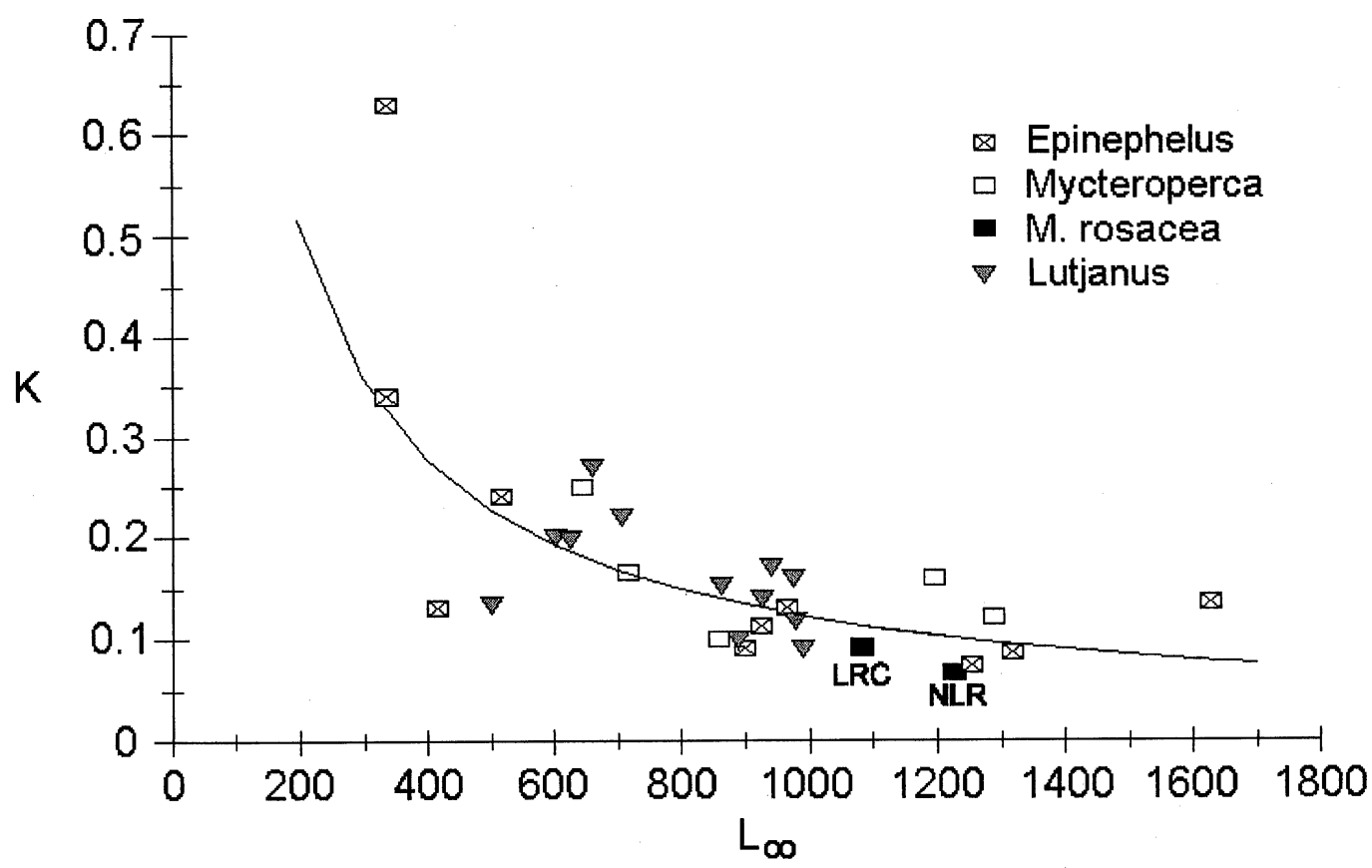

FIGURE 5. Growth performance $(\Phi)$ for several species of the families Serranidae and Lutjanidae (cited in Manooch 1987) and for $M$. rosacea by NLR (nonlinear regression) and LRC (linear regression).

(1983) developed the index $\Phi=\log k+$ $2 / 3 \log W_{\infty}$, called the "growth performance index" because it identifies specific kinds of growth in different taxonomic groups. An average value of $\Phi=1.66$ has been estimated for the family Serranidae, varying from 1.35 to 2.26 (Manooch 1987). We estimated $\Phi=1.735$ (using LRC) and $\Phi=1.693$ (using NLR) (Figure 5). Both values are consistent with the "growth performance index" of the family Serranidae.

The asymptotic size of the model (expressed as $L_{\infty}$ or $W_{\infty}$ ) has been generally defined as the average size a species would reach if growth were indefinite (Ricker 1975). Another interpretation was proposed by Pauly (1979), who argued that the asymptotic size should be equal to the average size of the oldest fish in a stock. The maximum length registered by us was $975 \mathrm{~mm}$ TL. It seems reasonable that the maximum length of $1000 \mathrm{~mm}$ reported by Thomson et al. (1987) is a good reference point of the asymptotic length in the southern Gulf of California, following the concept of Pauly (1979). In this context, the value of $L_{\infty}=1083 \mathrm{~mm}$ obtained by LRC seems more reasonable than the one estimated by the NLR method $\left(L_{\infty}=\right.$ $1226 \mathrm{~mm})$.

Manooch (1987) gave the values of $k$ for the family Serranidae, which vary from 0.074 to 0.63 per year. The leopard grouper has $k=0.066$ estimated by NLR, which is outside the range reported by Manooch, but the value estimated by LRC (0.092) is within the range.

It is important to stress that within the serranids the leopard grouper is one of the slowest growing species. This could be related to the feeding regime of the species. Buesa (1987) analyzed the growth rates of several species of demersal fish and found evidence that those with fish as a main item in their diet had slower growth rates than the ones with more diverse diets or the opportunistic ones. The leopard grouper has been 
classified as fully piscivorous (Hobson 1965), but Bermúdez-Almada and García-Laguna (1985) found that, besides fish, $M$. rosacea also feeds on crustaceans in a $2: 1$ ratio (fish: crustaceans). In spite of utilizing foods with high energetic content, the low growth rates of fish with this feeding regime are due to the large energetic cost of searching and chasing prey (Buesa 1987).

\section{ACKNOWLEDGMENTS}

We thank the fishermen of El Sargento and La Ventana for allowing us to sample their catches. We also are grateful to Richard Radtke and an anonymous reviewer who made important contributions on early drafts of the manuscript to improve its quality and clarity.

\section{Literature Cited}

Allen, G. R., and D. R. Robertson. 1994. Fishes of the tropical eastern Pacific. University of Hawai'i Press, Honolulu.

Beamish, R. J., and G. A. McFarlane. 1983. The forgotten requirement for age validation in fisheries biology. Trans. Am. Fish. Soc. 112:735-743.

Bermúdez-Almada, B., and G. García-Laguna. 1985. Hábitos alimenticios de los peces de las zonas rocosas de la Bahía de La Paz, Baja California Sur. B.S. thesis, Universidad Nacional Autónoma de México, México, D.F. [in Spanish].

Boehlert, G. W. 1985. Using objective criteria and multiple regression models for age determination in fishes. Fish. Bull. 83:103117.

Buesa, R. J. 1987. Growth rate of tropical demersal fishes. Mar. Ecol. Prog. Ser. 36:191-199.

Casselman, J. M. 1983. Age and growth assessment of fishes from their calcified structures-techniques and tools. In E. D. Prince and L. M. Pulos, eds. Proceedings of the International Workshop on Age Determination of Oceanic Pelagic Fishes: Tunas, Billfishes and Sharks. NOAA Tech. Rep. NMFS 8:1-17.

Devries, D. R., and R. V. Frie. 1996. Determination of age and growth. Pages 483-
512 in B. R. Murphy and D. W. Willis, eds. Fisheries techniques, 2nd ed. American Fisheries Society, Bethesda, Maryland.

Elorduy-Garay, J. F., and J. G. Díaz-Uribe. 1994. Age validation of Caulolatilus affinis, Gill 1865 (Pisces: Branchiostegidae) from the Gulf of California using otoliths. Sci. Mar. 58:277-287.

Heemstra, P. C. 1995. Serranidae. Pages 1201-1813 in W. Fisher, F. Krupp, W. Schneider, C. Sommer, K. E. Carpenter, and V. H. Niem, eds. Guía FAO para la identificación de especies para los fines de la pesca: Pacífico centro-oriental. Vol. 3. FAO, Rome [in Spanish].

Hobson, E. S. 1965. Diurnal-nocturnal activity of some inshore fishes in the Gulf of California. Copeia 3:291-302.

Manooch, C. S., III. 1987. Age and growth of snappers and groupers. Pages 329-374 in J. J. Polovina and S. Ralston, eds. Tropical snappers and groupers: Biology and fisheries management. Westview Press, Boulder, Colorado.

Manooch, C. S., and C. L. Drennon. 1987. Age and growth of yellow-tail snapper and queen triggerfish from the U.S. Virgin Islands and Puerto Rico. Fish. Res. 6:5368.

Munro, J. L., and D. Pauly. 1983. A simple method for comparing the growth of fishes and invertebrates. Fishbyte, ICLARM $1: 5-6$.

Pauly, D. 1979. Gill size and temperature as governing factors in fish growth: A generalization of von Bertalanffy's growth formula. Verh. Inst. Meereskunde, Univ. Kiel 63:1-156.

Prager, M. H., S. B. Saila, and C. W. Recksiek. 1989. FISHPARM: A microcomputer program for parameter estimation of nonlinear models in fishery science, 2nd ed. Old Dominion Univ., Oceanogr. Tech. Rep. 87-10: 1-18.

Ricker, W. E. 1975. Computation and interpretation of biological statistics of fish populations. Fish. Res. Board Can. Bull. 191:1-382.

. 1979. Growth rates and models. Pages 677-743 in W. S. Hoar, D. J. Ran- 
dall, and J. R. Brett, eds. Fish physiology. Vol. 8. Bioenergetics and growth. Academic Press, Orlando, Florida.

Rocha-Olivares, A., and V. Gómez-Muñoz. 1993. Validación del uso de otolitos para determinar la edad del huachinango del Pacífico Lutjanus peru (Perciformes: Lutjanidae) en la bahía de La Paz y aguas adyacentes, B.C.S., México. Cienc. Mar. 19:321-331.

Rodríguez-Medrano, M. C. 1990. Composición específica de la captura artesanal de escama de isla Cerralvo, B.C.S., México. B.S. thesis, Universidad Autónoma de Baja California Sur, La Paz, B.C.S., México [in Spanish].

Rosenblatt, R. H., and B. J. Zahuranec. 1987. The eastern Pacific groupers of the genus Mycteroperca; including a new species. Calif. Fish Game 53:228-245.

Simkiss, K. 1973. Calcium metabolism of fish in relation to ageing. Pages $1-12$ in T. B. Bagenal, ed. Ageing of fish. Unwin Brothers, Surrey, England.

Sparre, P., and S. C. Venema. 1992. Introduction to tropical fish stock assessment. FAO Fish. Tech. Pap. 306/1: 1-376.

Thomson, D. A., T. F. Lloyd, and A. N. Kerstitch. 1987. Reef fishes of the Sea of Cortez: The rocky-shore fishes of the Gulf of California. University of Arizona Press, Tucson.

Villavicencio, C. 1983. Distribución y abundancias relativas de la familia Serranidae en la Bahía de La Paz, B.C.S. Mem. VII Congr. Nac. Zool., Jalapa, Ver., México [in Spanish].

Williams, T., and B. C. Bedford. 1973. The use of otoliths for age determination. Pages 114-123 in T. B. Bagenal, ed. The ageing of fish. Unwin Brothers, Surrey, England. 